\title{
Cross sections of deuteron induced nuclear reactions on metal targets
}

\author{
F. Tárkányi1 ${ }^{1, a}$, A. Hermanne ${ }^{2}$, F. Ditrói ${ }^{1}$, S. Takács ${ }^{1}$, F. Szelecsényi ${ }^{1}$, B. Király ${ }^{1}$, J. Csikai ${ }^{1}$, M. Sonck ${ }^{2}$, M.S. Uddin ${ }^{3}$, \\ M. Hagiwara ${ }^{3}$, M. Baba ${ }^{3}$, T. Ido ${ }^{3}$, T. Ohtsuki ${ }^{3}$, Yu.N. Shubin ${ }^{4}$, S.F. Kovalev ${ }^{4}$, A.I. Dityuk ${ }^{4}$, and A.V. Ignatyuk ${ }^{4}$ \\ ${ }^{1}$ Institute of Nuclear Research of the Hungarian Academy of Sciences (ATOMKI), 4026 Debrecen, Hungary \\ 2 Cyclotron Laboratory, Vrije Universiteit Brussel (VUB), 1090 Brussels, Belgium \\ ${ }^{3}$ Cyclotron and Radioisotope Center (CYRIC), Tohoku University, Sendai 980-8578, Japan \\ ${ }^{4}$ Institute of Physics and Power Engineering (IPPE), Obninsk 249020, Russian Federation
}

\begin{abstract}
In the frame of a systematic study activation cross sections of a few hundred deuteron induced reactions were measured up to $50 \mathrm{MeV}$ on 25 metal targets having mostly natural isotopic composition. The majority of them have been measured for the first time. The recently measured data are still in the evaluation process. The experimental data were compared to the predictions of different theoretical codes. For better description developments of the theoretical models are in progress. The measured data find application in medical radioisotope production, thin layer activation and accelerator technology.
\end{abstract}

\section{Introduction}

Integral excitation functions for the production of residual nuclides with light charged particles constitute basic data for different applications. Presently, the most widely used processes are the proton induced nuclear reactions and their cross section data are well documented. Nowadays deuteron induced reactions also start to play an important role as the stripping process generates high production yields. Modern accelerators can produce high intensity deuteron beams. The deuteron induced reactions play an important role in setting up fast neutron sources (IFMIF), in thin layer activation technology (TLA), in medical radioisotope production, in activation analysis, etc. The Technical Meeting on Nuclear Data for the International Fusion Material Irradiation Facility (IFMIF) [1] gave a high priority for establishing a reliable database for deuteron activation data, in first instance on selected metals. It was proposed that IAEA considers a CRP to assemble a deuteron induced activation library. Experimental cross section data (in a broad mass region) are important for evaluation of developments of theoretical models on nuclear reactions as well. The predictivity of the presently used codes for deuteron induced reactions is moderate compared to proton and alpha induced reactions. A literature search shows that the status of the available cross section data for deuteron induced reactions (especially above $15-20 \mathrm{MeV}$ ) is very poor. No systematic studies were done earlier and the cross section data (except for a few well measured monitor and medically important reactions) show large discrepancies. For most applications, however, a complete experimental or calculated data set is required to optimize thick target yields.

To meet the requirements of different practical applications, about ten years ago we started to establish an experimental activation database by performing new experiments and a systematic survey of deuteron induced activation cross sections up to $50 \mathrm{MeV}$. The investigation started with production of standard data for monitoring the parameters (energy,

${ }^{a}$ Presenting author, e-mail: tarkanyi@atomki.hu intensity) of deuteron beams and for activation of machine parts for on-line wear measurements. By recognizing the importance of deuteron beams in medical isotope production and for production of high intensity fast neutrons, the investigations were further extended. We made systematic investigations of deuteron induced nuclear reactions on different gas targets, on "candidate" targets for medical radioisotope production [2,3], on different materials for thin layer activation [4] and on beam monitor reactions [5]. We summarize here the results for the most widely used technological metals, giving a status report on the investigated reactions while more experiments on for instance rare earth elements, on some metals and gases, are still in progress. In the near future the investigation will continue to complete the low and medium energy activation cross section database of deuteron induced reactions.

\section{Experimental}

The targets were irradiated with external beams of cyclotrons of Institute of Nuclear Research $(\mathrm{k}=20$, ATOMKI, Debrecen), Vrije Universiteit Brussel $(\mathrm{k}=40$, VUB, Brussels $)$, Tohoku University ( $\mathrm{k}=90, \mathrm{CYRIC}$, Sendai) and Université catholique de Louvain ( $\mathrm{k}=110$, UCL, Louven-la-Neuve).

The standard stacked foil irradiation method was used to measure the cross sections. The stacks were formed of different target foils, interlarded with $\mathrm{Al}, \mathrm{Ti}, \mathrm{Fe}, \mathrm{Cu}$ monitor foils to control the beam parameters. The excitation functions of the used monitor reactions were simultaneously re-measured over the whole energy range.

The gamma and X-ray spectra of the irradiated targets and monitor foils were measured without chemical separation using high-purity germanium detectors. Large source-detector distances helped to minimize the detector dead time, pile-up effects and coincidence losses and to decrease the possible geometrical effects caused by the extended dimensions (several millimetres) of the samples. The high radiation dose, the limitations of detector capacity and available data acquisition 
time influenced the optimization of the measuring time. More details can be found in the references listed in table 1 .

\section{Data evaluation}

\subsection{Particle energy}

The kinetic energy of the bombarding deuterons as a function of depth and its uncertainty were determined by calculation using the well measured primary energy and foil thickness data as input parameters. The energy is accurate within $\pm 0.5 \mathrm{MeV}$ in the front foils of the stacks and the uncertainty increases up to $\pm 1.5-2 \mathrm{MeV}$ at the end of a thick stack.

\subsection{Cross section}

As the gamma spectra were very complex an interactive spectrum analysis and iterative data evaluation (corrections for contribution of contaminating signals) were used for proper separation and identification of the different activation products. In case of any contradiction the spectrum unfolding and the data evaluation were repeated taking into account systematic trends, parent-daughter relationships, etc. Independent and cumulative elemental cross sections were calculated supposing the target to be monoisotopic.

Decay data were taken from recently updated databases. The absolute values of the cross sections are estimated to be accurate to $12 \%$ for the simple situations, and to about $25 \%$ for cross sections near the effective thresholds and where low activities had to be separated in complex gamma spectra.

\section{Nuclear model calculations}

In our case there were various aims in performing model calculations for the investigated reactions:

- to check the predictivity of different model codes using a-priori calculations;

- to have a preliminary knowledge on the behaviour of the excitation functions before the experiment and during the data evaluation;

- to select the contradicting experimental data measured earlier (effective threshold energies, energy shifts, significant differences in absolute values);

- to estimate contributions from nuclear reactions on different stable isotopes of the given element and from complete decays in the case of cumulative processes;

- to estimate radionuclide impurities from residual nuclei having unfavourable decay characteristics (large $\mathrm{T}_{1 / 2}$, no gamma, etc.);

- to prepare recommended database.

A variety of codes have been developed on the basis of equilibrium and pre-equilibrium reaction mechanisms. These codes have similar "physics" with different degrees of complexity in input data preparation and require different computing times. Some of them need detailed properties of nuclear reactions, including population of discrete levels. When the number of open channels is large it becomes impossible or very time consuming to provide all the required input data with sufficient accuracy and the advantages of these detailed codes may be reduced. We have found at the beginning and over the years that in such cases, the faster codes with less effort in input preparation are often more practical. However, the situation is complex. The success of the used codes also depend significantly on many other factors, like the availability of a proper expert for using dedicated codes, development of computer technology and the automation of recommended input parameters, which make easier the use of the more detailed codes. Therefore, taking into account our aims for the model calculations, we tried to make calculations with simpler codes in all cases. In those cases where it seemed to be the only promising solution we made more detailed calculations (isomeric yields, recommended data, to solve the large discrepancy in case of simple code). All calculations have been carried out without any parameter adjustment to see the general tendencies. The model calculations performed are collected in table 1 in the list of the investigated reactions.

The main problems of modelling of deuteron induced reactions are:

- small but systematic overestimation of $(\mathrm{d}, \mathrm{xn})$ reactions due to the improper selection of optical potential parameters and

- neglecting of direct processes in the case of (d,pxn) reactions which causes totally different shape of excitation functions.

For better description of the deuteron induced reactions the above mentioned codes and the selection of used input parameters are further developed in Obninsk and their improvement seems to be very promising. Our last experimental results were already compared with these modified codes. The systematic comparison with the earlier results is also in progress.

\section{Results}

The investigation includes reactions induced on the following 25 target elements: Al, Ti, V, Fe, Co, Ni, Cu, Zn, Y, Zr, Nb, Mo, Rh, Ag, Pd, Cd, In, Sn, Er, Yb, Pt, W, Ir, Au, Pb. A significant part of these data was reported for the first time.

\section{Discussion and conclusion}

In the frame of a systematic study activation cross sections of deuteron induced reactions were measured on 25 metal targets having mostly natural isotopic composition. The investigations have not been finished. New experiments are in the preparation phase to complete all investigated reactions up to $40 \mathrm{MeV}$, to investigate new targets and to investigate activation cross sections of short half-life residual nuclei. A significant part of the measurements has not been published yet due to the time consuming evaluation process.

The experimental data were compared with different theoretical codes, mostly with the ALICE-IPPE code but in a few 
Table 1. Investigated deuteron induced reactions on metals.

\begin{tabular}{|c|c|c|c|c|c|}
\hline Target & Products & $\begin{array}{c}E_{\max } \\
(\mathrm{MeV})\end{array}$ & Theory & Remark & Reference \\
\hline${ }^{27} \mathrm{Al}$ & $22,24 \mathrm{Na}$ & 50 & & & [7] \\
\hline${ }^{\text {nat }} \mathrm{Ti}$ & ${ }^{48} \mathrm{~V}^{44 \mathrm{~m}, 46,47,48} \mathrm{Sc}$ & 50 & & Data eval. in progr. & [7-10] \\
\hline${ }^{\text {nat }} \mathrm{V}$ & ${ }^{46,47,48} \mathrm{Sc},{ }^{48} \mathrm{~V},{ }^{51} \mathrm{Cr}$ & 40 & & Data eval. in progr. & \\
\hline${ }^{\text {nat }} \mathrm{Fe}$ & $55,56,57 \mathrm{Co},{ }^{52,54} \mathrm{Mn},{ }^{51} \mathrm{Cr}$ & 50 & & Data eval. in progr. & {$[7,9,11]$} \\
\hline${ }^{\text {nat }} \mathrm{Co}$ & ${ }^{55,56,57,58,60} \mathrm{Co},{ }^{59} \mathrm{Fe}$ & 40 & & Data eval. in progr. & \\
\hline${ }^{\text {nat } \mathrm{Ni}}$ & ${ }^{60,61,64} \mathrm{Cu},{ }^{56,57} \mathrm{Ni},{ }^{55,56,57,58,60,61} \mathrm{Co},{ }^{52,54,56} \mathrm{Mn},{ }^{51} \mathrm{Cr}$ & 50 & A-I, G, E-II & & {$[7,12-15]$} \\
\hline${ }^{\text {nat }} \mathrm{Cu}$ & ${ }^{62,63,65} \mathrm{Zn},{ }^{64} \mathrm{Cu},{ }^{57,65} \mathrm{Ni},{ }^{57,58,60} \mathrm{Co},{ }^{59} \mathrm{Fe}$ & 50 & A-I & & {$[7,11,16,17]$} \\
\hline nat $\mathrm{Zn}$ & ${ }^{66,67} \mathrm{Ga},{ }^{62,65,69 \mathrm{~m}} \mathrm{Zn},{ }^{61,64,67} \mathrm{Cu},{ }^{58} \mathrm{Co}$ & 50 & A-I & & {$[18]$} \\
\hline${ }^{89} \mathrm{Y}$ & ${ }^{88,89} \mathrm{Zr},{ }^{87 \mathrm{~m}, 87,88,90 \mathrm{~m}} \mathrm{Y},{ }^{85} \mathrm{Sr}$ & 40 & $\mathrm{~T}$ & & [19-21] \\
\hline${ }^{\text {nat }} \mathrm{Zr}$ & $90,91 \mathrm{~m}, 92 \mathrm{~m}, 95 \mathrm{~m}, 95 \mathrm{~g}, 96 \mathrm{Nb},{ }^{88,89,95,97} \mathrm{Zr},{ }^{86,87,88} \mathrm{Y}$ & 50 & A-I & & {$[21,22]$} \\
\hline${ }^{93} \mathrm{Nb}$ & ${ }^{90 m} \mathrm{Y},{ }^{90,91 \mathrm{~m}, 92 m} \mathrm{Nb},{ }^{93 \mathrm{~m}} \mathrm{Mo}$ & 40 & A-I & & {$[23,24]$} \\
\hline${ }_{\text {nat }, 100} \mathrm{Mo}$ & ${ }^{93 \mathrm{~m}, 99} \mathrm{Mo},{ }^{93 \mathrm{~m}, 93 \mathrm{~g}, 94 \mathrm{~m}, 94 \mathrm{~g}, 95 \mathrm{~m}, 95,96,99} \mathrm{Tc},{ }^{89,90,92 \mathrm{~m}, 95 \mathrm{~m}, 95 \mathrm{~g}, 96} \mathrm{Nb}$ & 50 & A-I & Data eval. in progr. & {$[25,26]$} \\
\hline${ }^{103} \mathrm{Rh}$ & ${ }^{103} \mathrm{Pd},{ }^{101 \mathrm{~m}, 101 \mathrm{~g}, 102 \mathrm{~m}, 102 \mathrm{~g}} \mathrm{Rh}$ & 21 & A-I ,G, E-II & & [27] \\
\hline${ }^{\text {nat } P d}$ & ${ }^{103,104 \mathrm{~m}, 104 \mathrm{~g}, 105,106 \mathrm{~m}, 110 \mathrm{~m}, 111} \mathrm{Ag},{ }^{100,101,109 \mathrm{~g}, 111 \mathrm{~m}} \mathrm{Pd},{ }^{100,101,102 \mathrm{~g}, 105,106} \mathrm{Rh}$ & 40 & A-I & Data eval. in progr. & [28] \\
\hline${ }^{\text {nat }} \mathrm{Ag}$ & ${ }^{105,106 m} \mathrm{Ag},{ }^{107,109} \mathrm{Cd}$ & 40 & $\mathrm{~T}$ & & [29] \\
\hline${ }^{n a t} \mathrm{Cd}$ & $\begin{array}{l}107 \mathrm{~g}, 108 \mathrm{~m}, 108 \mathrm{~g}, 109 \mathrm{~g}, 110 \mathrm{~m}, 110 \mathrm{~g}, 111 \mathrm{~g}, 112 \mathrm{~m}, 113 \mathrm{~m}, 114 \mathrm{~m}, 115 \mathrm{~m}, 116 \mathrm{ml} \mathrm{I}, \\
111 \mathrm{~m}, 115 \mathrm{~m}, 115 \mathrm{~g}, 117 \mathrm{~m}, 117 \mathrm{~g} \\
\mathrm{Cd},{ }^{105 \mathrm{~g}, 106 \mathrm{~m}, 110 \mathrm{~m}, 111 \mathrm{~g}} \mathrm{Ag}\end{array}$ & 40 & A-I, G,E-II & & [30] \\
\hline${ }^{\text {nat In }}$ & ${ }^{113 \mathrm{~g}, 117 \mathrm{~m}} \mathrm{Sn},{ }^{111 \mathrm{~g}, 113 \mathrm{~m}, 114 \mathrm{~m}, 115 \mathrm{~m}} \mathrm{In},{ }^{115 \mathrm{~m}, 115 \mathrm{~g}} \mathrm{Cd}$ & 40 & A-I & Data eval. in progr. & \\
\hline${ }^{\mathrm{nat}} \mathrm{Sn}$ & $117,118,120 \mathrm{~m}, 120 \mathrm{~g}, 122 \mathrm{~g}, 124 \mathrm{~g}, 125 \mathrm{Sb}$ & 40 & A-I & Data eval. in progr. & \\
\hline nat $\mathrm{Ta}$ & ${ }^{178,180,182} \mathrm{Ta},{ }^{179 m, 180 \mathrm{~m}, 181} \mathrm{Hf}$ & 40 & A-I & Data eval. in progr. & \\
\hline${ }^{\mathrm{nat}} \mathrm{W}$ & $181,182 \mathrm{~m}, 182 \mathrm{~g}, 183,184 \mathrm{~g}, 186 \mathrm{Re},{ }^{187} \mathrm{~W}$ & 50 & A-I, G,E-II & & [31] \\
\hline${ }^{192} \mathrm{Os}$ & ${ }^{182} \mathrm{Ir},{ }^{193} \mathrm{Os}$ & 21 & A-I, G, E-II & & [32] \\
\hline${ }^{\text {nat }} \mathrm{Ir}$ & ${ }^{188,189,191,193 \mathrm{~m}} \mathrm{Pt},{ }^{189,190 \mathrm{~g}, 192 \mathrm{~g}, 194 \mathrm{~m} 2} \mathrm{Ir}$ & 40 & A-I & & [33] \\
\hline${ }^{\text {nat }} \mathrm{Pt}$ & $191,192,193,194,195,196 \mathrm{~m}, 196,198,199 \mathrm{Au},{ }^{191,195 \mathrm{~m}, 197} \mathrm{Pt},{ }^{192} \mathrm{Ir}$ & 40 & A-I & & {$[34,35]$} \\
\hline${ }^{\text {nat }} \mathrm{Au}$ & ${ }^{197 \mathrm{~m}, 197 \mathrm{~g}} \mathrm{Hg},{ }^{196,198 \mathrm{~m}, 198 \mathrm{~g}} \mathrm{Au},{ }^{195 \mathrm{~m}} \mathrm{Pt}$ & 21 & & Data eval. in progr. & \\
\hline${ }^{\text {nat }} \mathrm{Tl}$ & ${ }^{202 \mathrm{~m}, 203 \mathrm{~g}, 204 \mathrm{~m}} \mathrm{~Pb},{ }^{202} \mathrm{Tl},{ }^{203} \mathrm{Hg}$ & 21 & & Data eval. in progr. & \\
\hline${ }^{\text {nat }} \mathrm{Pb}$ & ${ }^{203,204,205,206,207} \mathrm{Ba},{ }^{203} \mathrm{~Pb},{ }^{202} \mathrm{Tl}$ & 40 & A-I & Data eval. in progr. & [36] \\
\hline${ }^{\text {nat }} \mathrm{Pr}$ & ${ }^{139 \mathrm{~m}, 140,141} \mathrm{Nd},{ }^{142} \mathrm{Pr},{ }^{135,137 \mathrm{~m}, 139} \mathrm{Ce},{ }^{140} \mathrm{La}$ & 40 & & Data eval. in progr. & \\
\hline${ }^{\text {nat } H o ~}$ & ${ }^{166,169} \mathrm{Yb},{ }^{166,167,168} \mathrm{Tm}$ & 40 & A-I & Data eval. in progr. & \\
\hline${ }^{\text {nat }} \mathrm{Er}$ & ${ }^{163,165,166,167,168,170} \mathrm{Tm},{ }^{171} \mathrm{Er}$ & 40 & A-I, G, E-II & & {$[37,38]$} \\
\hline${ }^{\mathrm{nat}} \mathrm{Tm}$ & ${ }^{166,169} \mathrm{Yb},{ }^{166,167,168} \mathrm{Tm}$ & 40 & A-I, E-II & Data eval. in progr. & [39] \\
\hline${ }^{\text {nat }} \mathrm{Yb}$ & $170,171 \mathrm{mg}, 172 \mathrm{mg}, 173,174 \mathrm{~g}, 177 \mathrm{~g} \mathrm{Lu},{ }^{169,175,177 \mathrm{mg}} \mathrm{Yb}$ & 21 & A-I & & [40] \\
\hline
\end{tabular}

A-I = ALICE-IPPE, G = GNASH, E-II = EMPIRE-II, T = TALYS

cases the EMPIRE-II, GNASH and TALYS codes also were used. No significant differences were obtained on the results of the a priori calculations with different codes on the same reaction. On average the a priori theoretical calculations systematically overestimate the experimental data for the $(\mathrm{d}, \mathrm{xn})$ reactions. Good agreement can be reached by adjusting the optical model parameters. In case of the (d,pxn) reactions the situation is opposite: the experimental data are higher compared to the theory and the shape significantly differs. The difference is especially large for $(d, p)$ reactions. It seems that the observed cross sections of the $(\mathrm{d}, \mathrm{p})$ reaction cannot be reproduced below 20-30 MeV with the available statistical model codes because at low energies the direct stripping processes play a very important role. The development of the statistical model codes is in progress at IPPE by adding blocks to such codes for simulation of direct $(\mathrm{d}, \mathrm{p})$ and $(\mathrm{d}, \mathrm{t})$ transitions.

The measured cross section data find practical use in different applications:

Deuteron activation is important for IFMIF designers [1].

In wear measurement, using thin layer surface activation, mostly proton beams are used for the sample activation.
To produce with high yields radionuclides showing proper decay characteristics, deuteron induced reactions broaden the possibilities for some elements or are the only alternative for some marker isotopes [4].

The use of our data for evaluation of new production routes or for preparation of recommended data applied in the production of diagnostic and therapeutic radioisotopes are discussed in detail in $[2,3,6]$.

Taking into account that the standard reactions used to monitor charged particle beam intensity and energy are often based on simple metal targets, our precisely measured nuclear data and intercomparisons are extensively useful to prepare and to validate standard reactions $[5,6]$.

\section{References}

1. R. Forest, A. Mengoni, INDC-0478, IAEA, Vienna, 2005.

2. A. Hermanne et al. (these proceedings).

3. R. Capote et al. (these proceedings).

4. F. Ditroi et al. (these proceedings). 
5. S. Takacs et al. (these proceedings).

6. K. Gul et al., IAEA-TECDOC-1211, IAEA, Vienna, 2001, http://www.nds.or.at/medical.

7. S. Takacs et al., Nucl. Instrum. Meth. B 174, 235 (2001).

8. S. Takacs et al., Appl. Radiat. Isot. 48, 657 (1997).

9. A. Hermanne et al., Nucl. Instrum. Meth. B 161-163, 178 (2000).

10. S. Takacs et al., Nucl. Instrum. Meth. B (submitted).

11. S. Takacs et al., in Proceedings of the 14th International Conference on Application of Accelerators in Research and Industry, Denton, Texas, 1996, edited by J.L. Duggan, I.L. Morgan (AIP Woodbury, New York, 1997), AIP Conf. Proc. 392 (1997), p. 659.

12. S. Takacs et al., Radiochim. Acta 76, 15 (1997).

13. A. Hermanne et al., in Proceedings of the International Conference on Nuclear Data for Science and Technology, Trieste, 1997, edited by G. Reffo, A. Ventura, C. Grandi (IPS, Bologna, 1997), IPS Conf. Proc. 59, Vol. 2, p. 1262.

14. A. Hermanne et al., Nucl. Instrum. Meth. B (in press).

15. S. Takács et al., Nucl. Instrum. Meth. B (in press).

16. S. Takacs et al., in Proceedings of the 14th International Conference Application of Accelerators in Research and Industry, Denton, Texas, 1996, edited by J.L. Duggan, I.L. Morgan (AIP Woodbury, New York, 1997), AIP Conf. Proc. 392 (1997), p. 659.

17. S. Takacs et al., Nucl. Instrum. Meth. B 251, 56 (2006).

18. F. Tarkanyi et al., Nucl. Instrum. Meth. B 217, 531 (2004).

19. M.S. Uddin et al., in Proceedings of the International Conference on Application of Radiotracers in Chemical, Environmental and Biological Sciences, Kolkata, 2006, Vol. 2, edited by S. Lahiri, D. Nayak, A. Mukhopadhyay (Saha Institute of Nuclear Physics, Kolkata, 2006) p. 69.
20. M.S. Uddin et al., Radiochim. Acta 95, 187 (2007).

21. F. Tarkanyi et al., in Proceedings of the International Conference on Nuclear Data for Science and Technology, Santa Fe, 2004, edited by R.C. Haight, P. Talou, T. Kawano, AIP Conf. Proc. 769 (2005), p. 1658.

22. F. Tarkanyi et al., Nucl. Instrum. Meth. B 217, 373 (2004).

23. F. Ditrói et al., Nucl. Instrum. Meth. B 161, 172 (2000).

24. F. Tarkanyi et al., Nucl. Instrum. Meth. B 255, 297 (2007).

25. M. Sonck, in Proceedings of the International Conference on Nuclear Data for Science and Technology, Trieste, 1997, edited by G. Reffo, A. Ventura, C. Grandi (IPS, Bologna, 1997), IPS Conf. Proc. 59, Vol. 2, p. 637.

26. M. Sonck et al., in Proceedings of 15th International Conference Application of Accelerators in Research and Industry, Denton, 1998, edited by J.L. Duggan, I.L. Morgan (New York, Woodbury, AIP, 1999), AIP Conf. Proc. 475, (1999), p. 987.

27. A. Hermanne et al., Nucl. Instrum. Meth. B 187, 3 (2002).

28. A. Hermanne et al., Nucl. Instrum. Meth. B 217, 193 (2004).

29. M.S. Uddin et al., Appl. Radiat. Isot. 64, 1013 (2006).

30. F. Tarkanyi et al., Nucl. Instrum. Meth. B (in press).

31. F. Tarkanyi et al., Nucl. Instrum. Meth. B 211, 319 (2003).

32. F. Tarkanyi et al., Appl. Radiat. Isot. (submitted, 2006).

33. F. Tarkanyi et al., Nucl. Instrum. Meth. B 247, 210 (2006).

34. F. Tarkanyi et al., Nucl. Instrum. Meth. B 226, 490 (2004).

35. F. Ditroi et al., Nucl. Instrum. Meth. B 243, 20 (2006).

36. F. Ditroi et al., J. Radioanal. Nucl. Chem. (in press, 2007).

37. F. Tarkanyi et al., Nucl. Instrum. Meth. B (in press).

38. F. Tarkanyi et al., J. Labelled Cmpd. Radiopharm. (in press).

39. F. Tarkanyi et al., Appl. Radiat. Isot. 65, 663 (2007).

40. A. Hermanne et al., Nucl. Instrum. Meth. B 247, 223 (2006). 